\title{
Synovial Tissue Lymphoid Aggregates Are Associated With Response To Rituximab Therapy In Rheumatoid Arthritis Patients
}

\section{Matthew A Turk}

St Vincent's University Hospital

\section{Candice Low}

St Vincent's University Hospital

\section{Carl Orr}

St Vincent's University Hospital

\section{Richard Conway}

St Vincent's University Hospital

\section{Kieran Murray}

St Vincent's University Hospital

\section{Francis Young}

St Vincent's University Hospital

\section{Eamonn Molloy}

St Vincent's University Hospital

\section{Anne Barbara Mongey}

St Vincent's University Hospital

\section{Ursula Fearon}

Trinity Biomedical Sciences Institute

Douglas J. Veale ( $\sim$ douglas.veale@ucd.ie)

St Vincent's University Hospital

\section{Research Article}

Keywords: Rituximab, Rheumatoid Arthritis, Disease Activity, Synovial tissue, Lymphoid aggregates, Remission

Posted Date: February 15th, 2022

DOI: https://doi.org/10.21203/rs.3.rs-1275951/v2

License: (c) (1) This work is licensed under a Creative Commons Attribution 4.0 International License. Read Full License 


\section{Abstract}

Background: To evaluate the clinical and laboratory factors associated with long-term responses to rituximab therapy in patients with RA.

Methods: One hundred fourteen RA patients received intravenous Rituximab between 2003-2016. Prior to treatment, arthroscopy and synovial biopsy was performed on a subgroup of this cohort who had active knee arthritis. Demographic, clinical, and outcome data were collected prospectively and immunohistology was performed on synovial tissue biopsies.

Results: In the overall cohort, $89 \%$ of patients were seropositive for either RF (rheumatoid factor) or ACPA (anti-citrullinated protein antibodies). At baseline, median disease duration was 13.5 years. Seventy-four percent of patients had received a cSDMARD and two thirds had received a bDMARD before rituximab. Rituximab monotherapy was used in 34 patients, while 80 patients received rituximab-csDMARD combination therapy. Twenty-six of the 68 patients in remission (38\%) received rituximab monotherapy and $42 / 68(62 \%)$ received combination therapy with a csDMARD. Twenty-four of $39(62 \%)$ biologic naïve patients achieved remission on treatment with rituximab. Forty-four patients underwent an arthroscopy and synovial biopsy prior to treatment. Synovial tissue lymphoid aggregates (LA) were observed in 21 subjects, of which 17 (81\%) showed complete or partial remission in response to treatment with rituximab. The presence of LA was significantly associated with rituximab-induced remission in these patients $(p=0.007,0 R=7.286[1.737-30.555])$.

Conclusion: In this real world series, patients with RA demonstrate long-term, high response rates to rituximab therapy and synovial biopsy B-cell rich lymphoid aggregates are associated with a higher rate of good response.

\section{Introduction}

Rheumatoid arthritis (RA) is associated with the presence of circulating autoantibodies such as rheumatoid factor (RF) and anti-citrullinated proteins (ACPA), which may be present before clinical manifestations of disease [1]. The association with autoantibodies has led to focus on the role of activated B lymphocytes and plasma cells in RA pathogenesis. The anti-CD20 monoclonal antibody (rituximab) has been reported as a successful treatment for RA [2, 3].

The efficacy of Rituximab, both as induction and maintenance therapy, in the treatment of RA has now been the subject of several open and randomized controlled trials (RCTs) [4-13]. Rituximab has been demonstrated to be effective in early RA, as monotherapy, in combination with methotrexate or cyclophosphamide, and in tumour necrosis factor inhibitor (TNFi) inadequate responders [6-11]. Rituximab has also been shown to inhibit radiographic disease progression in RA [11, 12]. The duration of these RCTs and time to the primary endpoint, has been relatively short 24-52 weeks duration. The high quality RCTs that have been performed to date evaluating rituximab in RA provide strong evidence of efficacy and safety. However, while rightly considered the highest form of evidence on which to base 
treatment decisions, there are inherent limitations to RCTs; including the short time of follow up, lack of power to assess rare outcomes, and the inclusion of patients who are generally healthier and have better outcomes than the target population $[14,15]$.

Therefore, evidence in the form of real world, observational studies is useful for the evaluation of longterm treatment outcomes in routine patient populations. A number of registry-based studies have been reported [16-19], with large numbers of patients and follow-up duration of 2-4 years [19]. Good response to rituximab has been associated with a clinical factors such as ACPA titres and response at one year has been identified as a useful predictor of good response to TNFi bDMARDs [20-22]. The effects of rituximab on synovial tissue have been reported with some studies showing a reduction in the numbers of B cells [23-25] associated with a good clinical outcome. However, complete clearance of B cells from the synovium does not appear to be achieved following rituximab therapy [26, 27]. Importantly, while these studies report on B cell and plasma cell numbers, no studies to date have examined the presence or absence of lymphoid aggregates in the synovial tissue. More recently, studies suggest that gene profiling of synovial tissue may be useful in predicting the responses to rituximab treatment, with analysis of synovium with low numbers of B-cells associated with a transcriptomic profile that suggests an inadequate response to rituximab $[28,29]$. We performed a long-term, prospective, observational cohort study of all RA patients treated with rituximab at our institution over a period of 13 years. Specifically, we have analyzed synovial tissue biopsies for lymphoid aggregates, prior to starting treatment, on a subgroup of 40 patients.

\section{Patients And Methods}

\section{Patient Recruitment}

All patients attending outpatient clinics at the Department of Rheumatology, St. Vincent's University Hospital from 2003-2016 with a diagnosis of RA and who were scheduled to receive Rituximab were included in this observational study. All patients fulfilled the 1987 revised ACR criteria for the classification of RA [30]. All subjects gave fully informed written consent as approved by the St. Vincent's Healthcare Group Medical Research and Ethics Committee and all research was performed in accordance with the Declaration of Helsinki.

\section{Clinical Assessment}

Demographic and clinical characteristics, including age, gender, disease duration, current and previous medications, and response to treatment were recorded. Laboratory investigations including ESR, CRP, RF and ACPA were recorded at baseline. The CRP, 28-joint counts for tender and swollen joints and patient global health score (0-100mm visual analogue scale (VAS)) was completed at each subsequent visit. Disease activity was calculated using the DAS28-CRP [31]. Patients were followed up to the time of their most recent outpatient visit. The data in this study was recorded prospectively and entered a secure database. Remission was defined as DAS28-CRP $<2.6$ or meeting the 2011 ACR/EULAR remission criteria [32]. Patients with active disease (DAS28-CRP $\geq 3.2$ ) were classified as primary or secondary non- 
responders based on their initial and subsequent responses. If Rituximab was discontinued due to adverse events the severity and nature of these were recorded.

\section{Arthroscopy}

Arthroscopy and synovial biopsy was performed in a sub-group of patients prior to treatment under local anaesthesia using a Wolf $2.7 \mathrm{~mm}$ arthroscope, as previously described [33]. Patients were selected for arthroscopy based on the presence of active knee synovitis and provided written, fully informed consent for the procedure. The joint cavity was inspected, and the degree of synovitis and vascularity were scored on a VAS $(0-100 \mathrm{~mm})$ by experienced operators.

\section{Synovial tissue immunohistological staining}

Immunohistochemistry staining was performed using $3 \mu \mathrm{m}$ paraffin sections. Paraffin embedded sections were baked for 30 minutes at $90^{\circ} \mathrm{C}$, deparaffinised in xylene and rehydrated in alcohol and deionised water. Antigen retrieval was performed by heating sections in antigen retrieval solution $(15 \mathrm{ml}$ of $1 \mathrm{M}$ sodium citrate and $15 \mathrm{ml}$ of $1 \mathrm{M}$ citric acid in deionised water, $\mathrm{pH} 6.0$ ) in a pressure cooker. Slides were washed in PBS for 5 minutes. Non-specific binding was blocked using 10\% casein in PBS for 20 minutes. CD20 (DAKO, UK) and CD138 (DAKO, UK) primary antibodies were incubated on sections for 1 hours at room temperature. An IgG1 control antibody was used as a negative control. Following primary antibody incubation, endogenous peroxidase activity was blocked using $0.3 \% \mathrm{H} 2 \mathrm{O} 2$. Slides were incubated for 1 hour with horseradish peroxidase-conjugated secondary antibody (Dako). Colour was developed in diaminobenzidine solution (1:50; Dako) and counterstained with hematoxylin. Slides were mounted in Pertex media and analyzed using an established and validated semiquantitative scoring method 0-4 scale [34]. Lymphocyte-rich areas in synovial tissue were first described as 'resembling tonsil' [35]. More recently, it has been noted that lymphoid aggregates may become more highly organised into ectopic lymphoid follicle-like structures [36]. The presence or absence of lymphoid aggregates was determined in the synovial tissue, based on the original description of a lymphocyte aggregate.

\section{Statistical Analysis}

Descriptive statistics were reported as mean and standard deviation (SD), median and interquartile range (IQR), or number ( $\mathrm{n}$ ) and percentages as appropriate. For between group comparisons Chi-squared tests were used for categorical variables and independent samples t-tests for continuous variables. Student's ttests were used to analyse parametric data. For non-parametric data Wilcoxon signed rank test for related samples and Mann Whitney U test for unrelated samples were used.

Linear regression was used to assess the association between response to Rituximab and continuous variables. Correlations between response to Rituximab and dichotomous variables were assessed using binary logistic regression. Univariate analyses were performed to assess demographic and clinical predictors of rituximab response. Multiple logistic regression analyses were performed to model predictors of rituximab response. All factors that demonstrated $p<0.20$ in the univariate analyses were 
used to create a multivariate model and were evaluated with logistic regression analysis to model predictors of rituximab response.

Statistical significance was set at $\mathrm{P}<0.05$ throughout. All analyses were performed using IBM SPSS Statistics (IBM Corp. Released 2011. IBM SPSS Statistics for Windows, Version 27.0. Armonk, NY: IBM Corp.) and GraphPad Prism version 7.03 for Windows (GraphPad Software, La Jolla California USA, www.graphpad.com). Binary logistic regression was used to evaluate relationships between DAS28-CRP remission and lymphoid aggregates.

\section{Patient and Public Involvement}

Patients and public were not directly involved in the design of this research study, which was commenced over 15 years ago. However, CARD now has an active patient and public interaction, so that the analysis and results of this study have been discussed with our patient partners.

\section{Results}

There were a total of 114 RA patients ( 83 female and 31 male) with a mean age of 62 years and a median disease duration of 13.5 years were followed up (Table 1 ). 
Table 1

Baseline characteristics of 114 Rituximab treated patients. Data expressed as mean (SD), $\mathrm{n}(\%)$, or median (IQR) as indicated.

\begin{tabular}{|c|c|}
\hline Variable & Mean ( $( \pm S D)$ or Median (IQR) \\
\hline Age, years, mean $( \pm S D)$ & $62( \pm 13)$ \\
\hline Female, n (\%) & $83(73 \%)$ \\
\hline Disease duration, years, median (IQR) & $13.5(7,24.3)$ \\
\hline Previous csDMARDs, n (\%) & $84(74 \%)$ \\
\hline Previous bDMARDs, n (\%) & $75(66 \%)$ \\
\hline Serology, n (\%) & 97 (85\%) \\
\hline $\mathrm{RF}+$ & $73(64 \%)$ \\
\hline ACPA+ & $67(59 \%)$ \\
\hline $\mathrm{RF}+\mathrm{ACPA}+$ & $13(11 \%)$ \\
\hline \multicolumn{2}{|l|}{ RF-ACPA- } \\
\hline Tender Joint Count, median (IQR) & $7(3,15)$ \\
\hline Swollen Joint Count, median (IQR) & $5(1,11)$ \\
\hline ESR, mm/hr, median (IQR) & $32(16,57)$ \\
\hline CRP, mg/dL, median (IQR) & $11(4,27)$ \\
\hline \multicolumn{2}{|c|}{$\begin{array}{l}\text { *SD, standard deviation; IQR, interquartile range; cSDMARD, conventional synthetic disease modifying } \\
\text { anti-rheumatic drug; bDMARD, biologic disease modifying anti-rheumatic drug; RF, rheumatoid factor } \\
\text { ACPA, anti-citrullinated protein antibody; ESR, erythrocyte sedimentation rate; CRP, C-reactive protein }\end{array}$} \\
\hline
\end{tabular}

Overall, $74 \%$ of patients had received a csDMARD previously and $66 \%$ had received a bDMARD. Thirtyfour patients received rituximab monotherapy, while eighty received combination therapy rituximab plus a csDMARD. At baseline $85 \%$ of patients were RF positive; $64 \%$ anti-CCP antibody (ACPA) positive; $59 \%$ both RF and ACPA positive and $11 \%$ were autoantibody negative. Forty-four patients underwent an arthroscopy and synovial tissue biopsies were available to be evaluated for lymphoid aggregates (LA) in 40 subjects.

\section{Efficacy of Rituximab}

The maximum duration of follow-up was 12.8 years. DAS28-CRP remission was maintained by $68 \%$ of RA patients treated with rituximab, there were 15 primary non-responders, 24 secondary non-responders and 7 patients stopped due to adverse events (Figure 1). The patients maintained in remission on rituximab included $38 \%$ on monotherapy and $62 \%$ on combination therapy rituximab plus a csDMARD. 
Rituximab achieved equivalent outcomes in patients who had previously failed a bDMARD. In the bDMARD naïve patients $(n=39)$ remission was achieved in $62 \%$ of patients, while $59 \%$ bDMARDexperienced patients achieved remission and $41 \%$ did not. Fifty-five patients had previously failed 2 or more bDMARDs, $55 \%$ of whom achieved remission. There was no difference in any clinical or arthroscopic metrics between responders and non-responders before treatment with rituximab. In the 40 patients with evaluable synovial biopsy tissue LA positive for the $B$ cell marker CD20 (LA+) (Figure 2A), were observed in 21 subjects, while 19 were LA negative (LA-) (Figure 2B). Sustained remission was observed in $14 / 21(66 \%)$ LAt subjects and partial remission in $3 / 21(14 \%)$. In contrast, 19 subjects were LA-, only $3 / 19(15 \%)$ of whom had a sustained response, $4 / 19(21 \%)$ had a partial response and $12 / 19(63 \%)$ had no response.

\section{Predictors of Rituximab Response}

Binary logistic regression analysis was performed to assess predictors of response to rituximab. Variables analysed included RF positivity, RF titre, ACPA positivity and, titre, ESR, CRP, TJC, SJC, disease duration, number of previous csDMARDs failed, number of prior biologics failed, $L A$, and $B$ cell marker staining. The presence of $L A$ was the only factor significantly associated with remission in patients treated with rituximab $(p=0.007,0 R=7.286$ [1.737-30.555]) (Table 2).

Table 2

Binary logistic regression analysis of microscopic findings in patients who underwent arthroscopy

\begin{tabular}{|lll|}
\hline Variable & P value & OR $(95 \% \mathrm{Cl})$ \\
\hline Predictors of remission: & & \\
\hline CD20+ & NS & \\
\hline CD138+ & NS & 7.286 \\
\hline Lymphoid Aggregates & 0.007 & $(1.737-30.555)$ \\
\hline & & \\
\hline$*$ Remission is defined as Das28-CRP $\leq 2.6$. & \\
\hline$* *$ OR = odds ratio, DAS28-CRP = disease activity score 28 based on C-reactive protein. \\
\hline
\end{tabular}

\section{Safety of long-term Rituximab}

Seven patients stopped Rituximab due to adverse events over the course of the study. This represented $6 \%$ of all patients treated with rituximab. Of these 3 had hypersensitivity reactions, 2 stopped due to recurrent LRTIs, 1 due to neutropenia, and 1 due to severe herpes zoster infection. 4 patients had an adverse event on the first course of rituximab (3 hypersensitivity (1 on 1st infusion) and 1 herpes zoster), 3 patients developed an adverse event on the second course (2 LRTIs, 1 neutropenia). 


\section{Discussion}

In this study we evaluated long term outcomes in unselected RA patients treated with rituximab at our institution. Overall, we identified a good response to rituximab treatment, $68 \%$ of patients maintained DAS28-CRP remission over a mean of 3.1 years follow up, significantly longer than reported in RCTs. These data suggest rituximab compares favorably to remission responses, in the real-world setting, that we have reported with other bDMARDs [21]. Importantly, patients who had previously failed other bDMARDs demonstrated good response rates to rituximab, regardless of the number previously tried. Remission was achieved in $59 \%$ of those having failed one and $55 \%$ of those having failed two or more bDMARDs compared with $62 \%$ of biologic naïve patients. As reported previously the unique mode of action of rituximab, depleting $B$ cells, it may facilitate a better response in those RA patients with $B$ cell rich synovial biospies, especially in those with B cell rich lymphoid aggregates. Interestingly, in contrast to the many open studies which found a higher response in ACPA+ RA patients we did not find any significant differences in clinical, serological, or macroscopic arthroscopy characteristics between rituximab responders and non-responders.

Our data support the original observational and RCT studies showing a good response to rituximab in patients with RA [6-13] and the persistence of response as reported by the British Society for Rheumatology Biologics Register (BSRBR-RA) [17]. The latter study evaluated persistence with rituximab treatment after 4 years in 1629 patients with a median disease duration of 12 years, in which the majority of patients were receiving concurrent csDMARDs. The authors found $60 \%$ of patients remained on rituximab treatment after 4 years. Rituximab had similar efficacy whether used as a first or second biologic in RA in their cohort. The Belgian MIRA registry reported a continuation rate of $67 \%$ in 649 patients over 1.8 years with a mean baseline disease duration over 12 years. All patients were receiving concurrent methotrexate and had received prior biologic treatment, with $54 \%$ receiving one, $32 \%$ receiving two, and $13 \%$ having $>2$ prior biologics [18]. The German RABBIT registry reported on 907 patients with a mean disease duration of 14 years. $32 \%$ of patients received monotherapy and $68 \%$ combination with methotrexate or leflunomide, the mean number of prior biologics was 1.5. They demonstrated positive outcomes with only $18 \%$ of patients switching to an alternative biologic over 3 years of treatment [16]. Using similar methodology, an Australian study analysed 167 patients treated with Rituximab over 2.7 years[19]. The median disease duration was 12 years and $78 \%$ of patients had one or more prior biologic. These data for rituximab suggest it is being used as a second or third line biologic for RA patients in the 'real world' setting. We report similar results with over $60 \%$ of RA patients obtaining a significant clinical response over long-term follow up suggesting that if we can predict those patients who will respond, then it would be useful to introduce rituximab earlier in the treatment of RA patients.

In addition, our data suggests that if B cell depletion in the synovial LA, regardless of serotype, is an important part of the mechanism of action of rituximab, then synovial tissue biopsy should be used to guide the selection of candidates for rituximab therapy. 
The main strength of our data over the previous registry studies is our detailed measurement of clinical and response data at the individual patient level. We also report on long term response rates up to 13 years in some patients. In addition to our clinical data, our research provides unique target tissue data from arthroscopies in, with immunohistological features of LA associated with a higher positive response to treatment.

Several studies have attempted to establish predictors of response in RA patients receiving rituximab therapy. A combination of data obtained from 10 registries in Europe showed that positive ACPA status, fewer failed prior DMARDs, single previous biologic use, and lower baseline DAS-28 independently predicted EULAR good response at 6 months [37]. The 6-month multicenter open-label rituximab retreatment dose study (SMART) looked at 208 refractory RA patients and found that presence of ACPA or RF, and an elevated serum lgG level were independently associated with more favorable clinical response [38]. Both studies find an association between autoantibody status and short-term response to rituximab. The BSRBR-RA reported baseline RF status as the only predictor of response to rituximab, although they did not have data on, and therefore could not evaluate, ACPA status[17]. Similarly, a study cohort comprised of 1,008 RA patients from two independent RCTs (SERENE and REFLEX) demonstrated positivity for RF or ACPA in combination with an elevated CRP at baseline to predict a more favourable clinical response to rituximab [39]. Rituximab's success in treatment has been attributed to the degree of B cell depletion, particularly in the 2 weeks following administration rather than the dose itself [40]. In contrast to previous studies, in our cohort, no baseline features were predictors of response to rituximab. In particular, neither RF or ACPA positivity (nor titer) were predictive of response, this may reflect the realworld nature of our patients or the long-term response that we used in the analysis. However, we did find significant links between B-cell staining in the synovial LA, a feature not evaluated in any previous study, and successful treatment with RTX. Previous work from our group has shown an association between ACPA positivity and both synovial B cell LA in patients with RA [41]. We do not routinely measure serum IgG or markers of circulating B-cell depletion, so were unable to evaluate changes in these markers in response to rituximab treatment.

Our findings have several important implications for clinical practice. By demonstrating high levels of long-term persistence, efficacy and safety we confirm a role for rituximab as an important bDMARD for use in the real-world setting. Rituximab has usually been utilized in seropositive patients; however, our data demonstrate that it may also be an effective option in seronegative RA patients. This data mirrors results from previous studies which show good response to rituximab in both seropositive and seronegative patients, albeit a stronger response in seropositive patients [42]. Indeed careful analysis of previous results shows that while seropositive patients have a higher good EULAR response rate of $70 \%$, seronegative patients have a good EULAR response rate as high as 48\% [37]. The use of synovial biopsy B-cell rich LA maybe a useful marker of patients who may have a good response to rituximab.

There are limitations to our study. We have evaluated a relatively small number of patients managed over a long time period in routine clinical practice. There are inherent limitations to the observational method in evaluating patients outside of the rigorously controlled setting of a RCT. In order to maximise the 
duration of our follow up data we have recorded responses up to the time of last follow-up, this has resulted in a wide range of follow up duration (median 3.1 years, maximum 12.8 years). This was a single-centre study, and this may limit the external validity of the findings and applicability to other populations.

\section{Conclusions}

In conclusion we have shown that rituximab is an effective long-term treatment achieving remission, sustained in over $60 \%$ of RA patients up to 13 years. Prior bDMARD treatment does not appear to appreciably diminish the likelihood of good response. Interestingly, the presence of lymphoid aggregates in synovial tissue biopsies are significantly associated with a higher response.

\section{List Of Abbreviations}

ACPA anti-citrullinated protein antibody

ACR American College of Rheumatology

bDMARD biologic disease modifying anti-rheumatic agent

CD cluster of differentiation

CRP C-reactive protein

CSDMARD conventional synthetic disease modifying anti-rheumatic agent

DAS disease activity score

DMARD disease modifying anti-rheumatic agent

ESR erythrocyte sedimentation rate

EULAR European Alliance of Associations for Rheumatology

IQR interquartile range

LA lymphoid aggregate

RA rheumatoid Arthritis

RF rheumatoid factor

SD standard deviation

SJC swollen joint count 
TJC tender joint count

\section{Declarations}

Ethics approval and consent to participate

This study was approved by St. Vincent's University Hospital Ethics Committee

Consent for publication

The authors consent for this article to be published.

Availability of Data and Materials

Data will be made available on reasonable request. There are no additional unpublished data.

Competing interests

The authors have no competing interests to declare

\section{Funding}

No funding was received for the work reported in this manuscript

\section{Author's Contributions}

MAT collected and analysed data, performed statistical analysis, and wrote the manuscript.

CL planned the study, collected and analysed data, and wrote the manuscript

$\mathrm{CO}, \mathrm{RC}, \mathrm{KM}$ and FY collected and analysed data, revised the manuscript for intellectual content and approved the final version.

$\mathrm{EM}, \mathrm{ABM}, \mathrm{UF}$, and DJV planned the study, contributed to the data analysis, revised the manuscript for intellectual content and approved the final version.

\section{Acknowledgements}

We would like to thank all the patients and the staff at the Bone and Joint unit of St. Vincent's University Hospital.

\section{References}

1. Mclnnes IB, Schett G. The pathogenesis of rheumatoid arthritis. N Engl J Med 2011;365:2205-19.

2. Edwards JC, Cambridge G. Sustained improvement in rheumatoid arthritis following a protocol designed to deplete B lymphocytes. Rheumatology (Oxford) 2001;40:205-11. 
3. Porter D, van Melckebeke J, Dale J, et al. Tumour necrosis factor inhibition versus rituximab for patients with rheumatoid arthritis who require biological treatment (ORBIT): an open-label, randomised controlled, non-inferiority, trial. Lancet 2016;388:239-47.

4. De Vita S, Zaja F, Sacco S, et al. Efficacy of selective B cell blockade in the treatment of rheumatoid arthritis: evidence for a pathogenetic role of B cells. Arthritis Rheum 2002;46:2029-33.

5. Kneitz $C$, Wilhelm M, Tony HP. Improvement of refractory rheumatoid arthritis after depletion of $B$ cells. Scand J Rheumatol 2004;33:82-6.

6. Edwards JCW, Szczepanski L, Szechinski J, et al. Efficacy of B-cell-targeted therapy with rituximab in patients with rheumatoid arthritis. N Engl J Med 2004;350:2572-81.

7. Emery P, Fleischmann R, Filipowicz-Sosnowska A, et al. The efficacy and safety of rituximab in patients with active rheumatoid arthritis despite methotrexate treatment: results of a phase IIB randomized, double-blind, placebo-controlled, dose-ranging trial. Arthritis Rheum 2006;54:1390-400. doi:10.1002/art.21778

8. Emery P, Deodhar A, Rigby WF, et al. Efficacy and safety of different doses and retreatment of rituximab: a randomised, placebo-controlled trial in patients who are biological naive with active rheumatoid arthritis and an inadequate response to methotrexate (Study Evaluating Rituximab's Efficacy in MTX iNadequate rEsponders (SERENE)). Ann Rheum Dis 2010;69:1629-35.

9. Cohen SB, Emery P, Greenwald MW, et al. Rituximab for rheumatoid arthritis refractory to anti-tumor necrosis factor therapy: Results of a multicenter, randomized, double-blind, placebo-controlled, phase III trial evaluating primary e

10. Mease PJ, Cohen S, Gaylis NB, et al. Efficacy and safety of retreatment in patients with rheumatoid arthritis with previous inadequate response to tumor necrosis factor inhibitors: results from the SUNRISE trial. J Rheumatol 2010;37:917-27.

11. Tak PP, Rigby WF, Rubbert-Roth A, et al. Inhibition of joint damage and improved clinical outcomes with rituximab plus methotrexate in early active rheumatoid arthritis: the IMAGE trial. Ann Rheum Dis 2011;70:39-46.

12. Rubbert-Roth A, Tak PP, Zerbini C, et al. Efficacy and safety of various repeat treatment dosing regimens of rituximab in patients with active rheumatoid arthritis: results of a Phase III randomized study (MIRROR). Rheumatology (Oxford) 2010;49:1683-93.

13. Greenwald MW, Shergy WJ, Kaine JL, et al. Evaluation of the safety of rituximab in combination with a tumor necrosis factor inhibitor and methotrexate in patients with active rheumatoid arthritis: results from a randomized controlled trial. Arthritis Rheum 2011;63:622-32.

14. Prasad V, Berger VW. Hard-Wired Bias: How Even Double-Blind, Randomized Controlled Trials Can Be Skewed From the Start. Mayo Clin Proc 2015;90:1171-5.

15. Conway R, Coughlan RJ, Low C, et al. Reply: To PMID 24757133. Arthritis Rheumatol 2014;66:2642.

16. Richter A, Strangfeld A, Herzer $P$, et al. Sustainability of rituximab therapy in different treatment strategies: results of a 3-year followup of a German biologics register. Arthritis Care Res (Hoboken) 2014;66:1627-33. 
17. Oldroyd AGS, Symmons DPM, Sergeant JC, et al. Long-term persistence with rituximab in patients with rheumatoid arthritis. Rheumatology (Oxford) 2018;57:1089-96.

18. De Keyser F, Hoffman I, Durez P, et al. Longterm followup of rituximab therapy in patients with rheumatoid arthritis: results from the Belgian MabThera in Rheumatoid Arthritis registry. $\mathrm{J}$ Rheumatol 2014;41:1761-5.

19. Nicholls D, Zochling J, Boers A, et al. A retrospective chart review of the use of rituximab for the treatment of rheumatoid arthritis in Australian rheumatology practice. Int J Rheum Dis 2014;17:75561.

20. Stradner MH, Dejaco C, Brickmann K, et al. A combination of cellular biomarkers predicts failure to respond to rituximab in rheumatoid arthritis: a 24-week observational study. Arthritis Res Ther 2016;18:190.

21. Murray K, Turk M, Alammari Y, et al. Long-term remission and biologic persistence rates: 12-year realworld data. Arthritis Res Ther 2021;23:25.

22. Narvaez J, Díaz-Torné $C$, Ruiz JM, et al. Predictors of response to rituximab in patients with active rheumatoid arthritis and inadequate response to anti-TNF agents or traditional DMARDs. Clin Exp Rheumatol 2011;29:991-7.

23. Vos K, Thurlings RM, Wijbrandts CA, et al. Early effects of rituximab on the synovial cell infiltrate in patients with rheumatoid arthritis. Arthritis Rheum 2007;56:772-8.

24. Teng YK, Levarht EW, Hashemi M, et al. Immunohistochemical analysis as a means to predict responsiveness to rituximab treatment. Arthritis Rheum. 2007; 56:3909-18.

25. Thurlings RM, Vos K, Wijbrandts CA, Zwinderman AH, et al. Synovial tissue response to rituximab: mechanism of action and identification of biomarkers of response. Ann Rheum Dis. 2008;67:91725.

26. Kavanaugh A, Rosengren S, Lee SJ, et al. Assessment of rituximab's immunomodulatory synovial effects (ARISE trial). 1:clinical and synovial biomarker results. Ann Rheum Dis. 2008;67:402-8.

27. Teng YK, Levarht EW, Toes RE, et al. Residual inflammation after rituximab treatment is associated with sustained synovial plasma cell infiltration and enhanced B cell repopulation. Ann Rheum Dis. 2009;68:1011-6.

28. Hogan VE, Holweg CT, Choy DF, et al. Pretreatment synovial transcriptional profile is associated with early and late clinical response in rheumatoid arthritis patients treated with rituximab. Ann Rheum Dis. 2012;71:1888-94.

29. Humby F, Durez $P$, Buch $M$, et al. Rituximab versus Tocilizumab in anti-TNF inadequate responder 1 patients with Rheumatoid Arthritis (R4RA): a stratified, biopsy-driven, multi-centre, randomised, open label, controlled clinical trial - 16 week outcomes. Lancet. 2021;Jan 23;397:305-17.

30. Arnett FC, Edworthy SM, Bloch DA, et al. The American Rheumatism Association 1987 revised criteria for the classification of rheumatoid arthritis. Arthritis Rheum 1988;31:315-24.

31. Wells G, Becker J-C, Teng J, et al. Validation of the 28-joint Disease Activity Score (DAS28) and European League Against Rheumatism response criteria based on C-reactive protein against disease 
progression in patients with rheumatoid arthritis, and comparison with the DAS28 based on erythrocyte sedimentation rate. Ann Rheum Dis 2009;68:954-60.

32. Felson DT, Smolen JS, Wells G, et al. American College of Rheumatology/European League against Rheumatism provisional definition of remission in rheumatoid arthritis for clinical trials. Ann Rheum Dis 2011;70:404-13.

33. Orr CK, Vieira-Sousa E, Fonseca JE, Veale D. Arthroscopic Guided Synovial Biopsies. Front Med (Lausanne). 2021 Feb 11;7:604582.

34. Rooney T, Bresnihan B, Andersson $\mathrm{U}$, et al. Microscopic measurement of inflammation in synovial tissue: inter-observer agreement for manual quantitative, semiquantitative and computerised digital image analysis. Ann Rheum Dis. 2007;66:1656-60.

35. Iguchi T, Ziff M. Electron microscopic study of rheumatoid synovial vasculature. Intimate relationship between tall endothelium and lymphoid aggregation. J Clin Invest. 1986;77:355-61.

36. Bombardieri M, Lewis M, Pitzalis C. Ectopic lymphoid neogenesis in rheumatic autoimmune diseases. Nat Rev Rheumatol. 2017;13:141-54.

37. Chatzidionysiou K, Lie E, Nasonov E, et al. Highest clinical effectiveness of rituximab in autoantibody-positive patients with rheumatoid arthritis and in those for whom no more than one previous TNF antagonist has failed: pooled data from 10 European registries. Ann Rheum Dis 2011;70:1575-80.

38. Sellam J, Hendel-Chavez H, Rouanet S, et al. B cell activation biomarkers as predictive factors for the response to rituximab in rheumatoid arthritis: a six-month, national, multicenter, open-label study. Arthritis Rheum 2011;63:933-8.

39. Lal P, Su Z, Holweg CTJ, et al. Inflammation and autoantibody markers identify rheumatoid arthritis patients with enhanced clinical benefit following rituximab treatment. Arthritis Rheum 2011;63:3681-91.

40. Vital EM, Rawstron AC, Dass S, et al. Reduced-dose rituximab in rheumatoid arthritis: efficacy depends on degree of B cell depletion. Arthritis Rheum 2011;63:603-8.

41. Orr C, Najm A, Biniecka M, et al. Synovial Immunophenotype and Anti-Citrullinated Peptide Antibodies in Rheumatoid Arthritis Patients: Relationship to Treatment Response and Radiologic Prognosis. Arthritis Rheumatol 2017;69:2114-23.

42. Isaacs JD, Cohen SB, Emery P, et al. Effect of baseline rheumatoid factor and anticitrullinated peptide antibody serotype on rituximab clinical response: a meta-analysis. Ann Rheum Dis 2013;72:329-36.

\section{Figures}


A

$$
\begin{aligned}
& \mathrm{RF}+/ \mathrm{ACPA}+ \\
& \mathrm{RF}+/ \mathrm{ACPA}- \\
& \mathrm{RF}-/ \mathrm{ACPA}+ \\
& \mathrm{RF}-/ \mathrm{ACPA}-
\end{aligned}
$$

\section{Rituximab Responders}

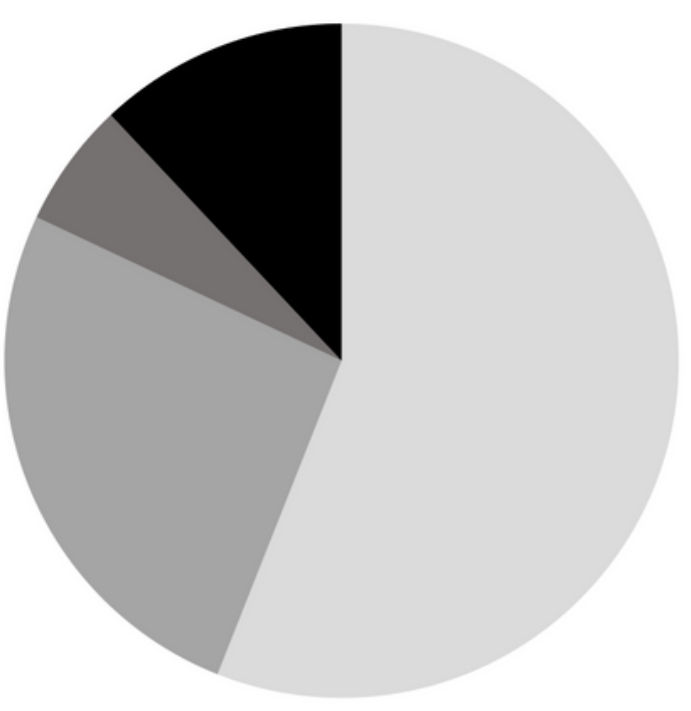

B

Rituximab Non-Responders

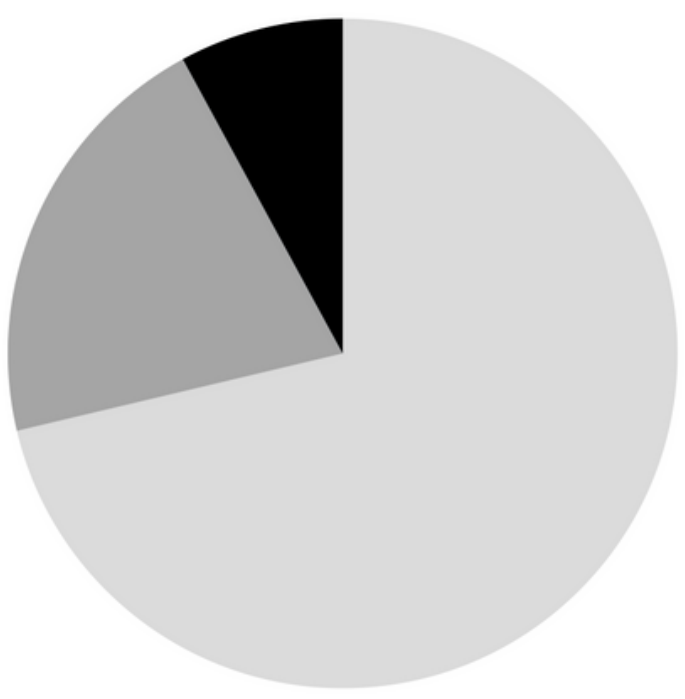

Stopped Rituximab

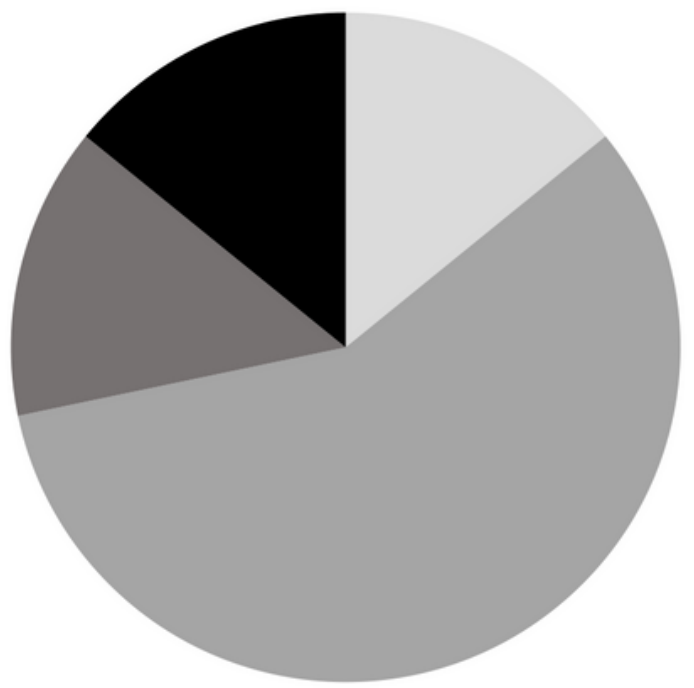

\section{Figure 1}

Serostatus among (A) responders, (B) non-responders, and (C) those who stopped taking rituximab. 

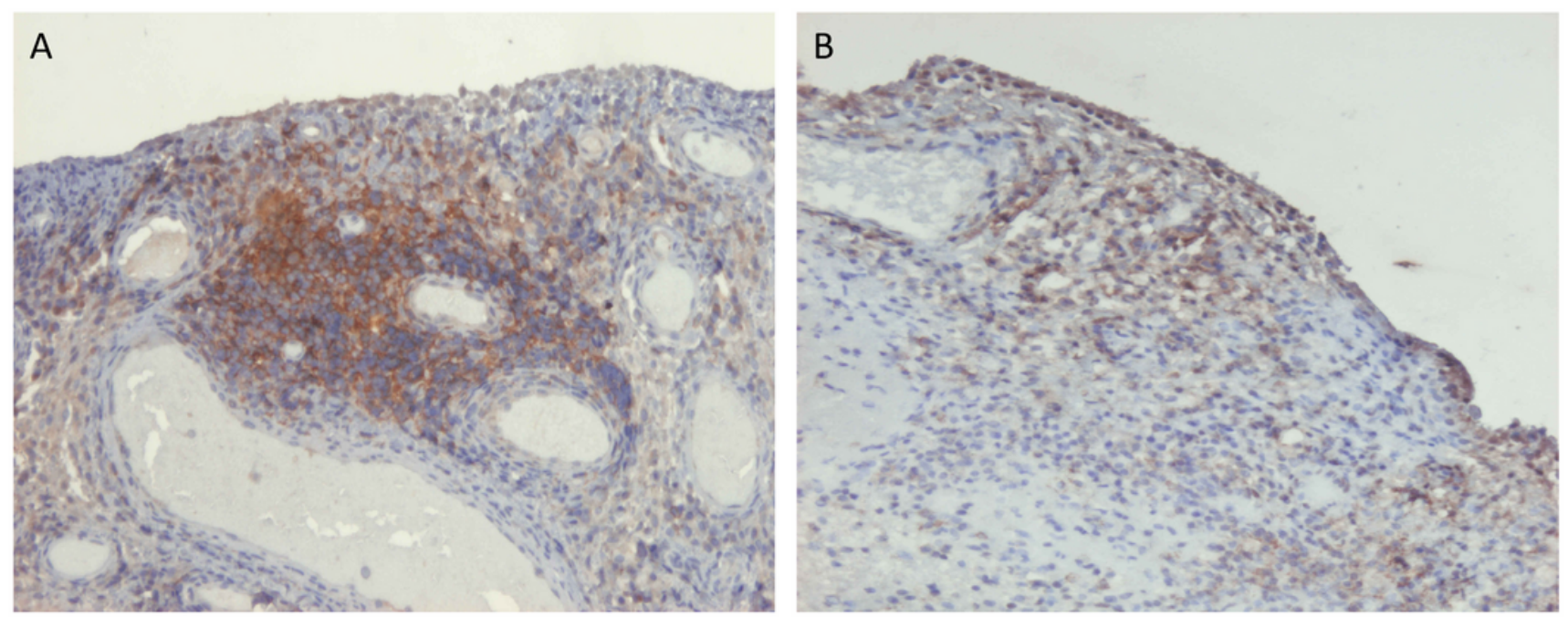

\section{Figure 2}

Immunostaining of rheumatoid arthritis synovial tissues for CD20+ B cells showing a B cell rich lymphoid aggregate in $A$, and a sparse diffuse $B$ cell infiltrate without any aggregates in $B$. (Original magnification $x$ 10). 